\title{
POR UMA PEDAGOGIA DO BELO: EDUCAÇÃO, ESTÉTICA E SENSIBILIDADES
}

\author{
FOR A PEDAGOGY OF THE BEAUTIFUL: AESTHETIC, EDUCATION \\ AND SENSITIVITIES
}

\author{
Graciele Maria Coelho de Andrade Gomes \\ Doutoranda em Educação - Universidade Federal de Pernambuco - UFPE \\ Recife, Pernambuco, Brasil \\ gracieleekelner@gmail.com
}

Mário de Faria Carvalho

Doutor em Sciences Sociales - Université René Descartes - Paris V - Professor Associado - Universidade Federal de Pernambuco - UFPE

Caruaru, Pernambuco, Brasil mariofariacarvalho@gmail.com

\begin{abstract}
Resumo: Neste estudo interessamo-nos em problematizar o argumento kantiano sobre o gosto/juízo fora do objeto. Para tanto, é rediscutido o que é o ‘belo' e ensaiada a proposição de uma categoria teórica denominada de 'pedagogia do belo' como forma de pensar a educação estética enquanto um saber que acontece a partir da consideração das sensibilidades e das subjetividades. Propomos que, na pedagogia do belo, a obra de arte opera como um artefato, uma metáfora mediadora. Assim, esta categoria dimensiona a reestruturação do consciente que assente ao imaginário; articula aspectos fundantes sobre as sensibilidades no fruir da existência e das experiências; permite a formação de valores estético-éticos por meio da contemplação sensível dos elementos simbólicos. A potência da pedagogia do belo remete ao modo pelo qual o conhecimento pode ser suscitado a partir da arte. Demonstra um caminho no qual o ato de conhecer decorre das trocas, dos afetos e da experiência.
\end{abstract}

Palavras Chave: Educação. Estética. Pedagogia do belo. Sensibilidades. Subjetividades.

\begin{abstract}
In this study we are interested in problematizing the Kantian argument about taste/judgment outside the object. Therefore, what is 'beautiful' is re-discussed and the proposition of a theoretical category called 'pedagogy of the beautiful' is rehearsed as a way of thinking about aesthetic education as a knowledge that happens from the consideration of sensitivities and subjectivities. We propose that, in the pedagogy of the beautiful, the work of art operates as an artifact, a mediating metaphor. Thus, this category measures the restructuring of the conscious that is based on the imaginary; articulates fundamental aspects about the sensibilities in enjoying existence and experiences; it allows the formation of aesthetic-ethical values through the sensitive contemplation of symbolic elements. The power of the pedagogy of the beautiful refers to the way in which knowledge can be raised from art. It demonstrates a path in which the act of knowing results from exchanges, affections and experience.
\end{abstract}

Key-words: Education. Aesthetics. Pedagogy of the beautiful. Sensitivities. Subjectivities.

\section{Para citar - (ABNT NBR 6023:2018)}

GOMES, Graciele Maria Coelho de Andrade; CARVALHO, Mário de Faria. Por uma pedagogia do belo: educação, estética e sensibilidades. Eccos - Revista Cientifica, São Paulo, n. 53, p. 1-19, e16647, abr./jun. 2020. Disponível em: https://doi.org/10.5585/eccos.n53.16647. 


\section{Introdução}

A Estética, enquanto campo do saber, tem suscitado diversas reflexões ao longo da história. Diferentes perspectivas filosóficas foram idealizadas na busca por refletir a sua base epistêmica. A partir do século XVIII, no Ocidente, uma nova cultura de relação entre os saberes, uma nova episteme, aparece de modo simultâneo em locais distintos e suscitada por pensadores(as) diversos(as), os(as) quais propuseram ideias para além da racionalidade. Hermann (2005), Johann Gottfried von Herder, Friedrich Schiller, Jean-Jacques Rousseau, Friedrich Wilhelm Joseph von Schelling e Friedrich Hölderlin são alguns dos filósofos e poetas que atuaram em prol da valorização dos sentimentos e da atividade criadora do espírito, que resistiram à pura racionalidade do saber.

Neste estudo partimos da reflexão estabelecida por Kant (2015) em sua obra A crítica do Juízo, na qual busca entender o que é o belo e que, então, insere a discussão sobre as subjetividades no estudo da estética para problematizar o que se pode considerar como uma outra perspectiva teórica para pensar a relação entre subjetividade e arte (SCHILLER, 2017). Interessamo-nos em questionar o argumento kantiano sobre a subjetividade fundada no gosto/juízo fora do objeto. São acrescentadas à discussão as reflexões de Friedrich Schiller (2017) sobre as influências da arte e do gosto na formação das pessoas, sobretudo a partir de sua obra Educação Estética do Homem. Nesta obra, Schiller (2017) se afasta das ideias kantianas para introduzir outro sentido sobre o belo. Para ele, o belo constrói-se em oposição ao que é estático. É um objeto primoroso e agradável que se organiza em torno do sentido e do entendimento antecipador, pois, ao cogitar o belo pelo belo, abre-se caminho para a experiência fundada nas subjetividades.

Cada pessoa se envolve e reside na experiência do belo de acordo com o seu estado de espírito. Pode-se falar em uma contemplação pela qual se alcança a liberdade com base na própria projeção simbólica, tão-somente. Neste estudo argumentamos que o belo instiga a percepção emocional do mundo no espírito do ser. Em outras palavras, faz com que a pessoa alcance um estado de liberdade irrestrita, tornando-se equilibrada e interligada à sua interioridade e, também, à exterioridade (SÜSSEKIND, 2011).

A manifestação do belo acontece na relação simbólica entre a pessoa e o objeto. Assim, localizamos o belo enquanto categoria central no estudo da dimensão epistêmica da estética. As reflexões propostas decorrem de uma perspectiva filosófica na qual a estética é considerada como um caminho para o conhecer e que acontece a partir da consideração das sensibilidades e das subjetividades envolvidas. 
Portanto, apresentaremos alguns contornos introdutórios sobre a pedagogia do belo. Partimos de questões relacionadas à formação moral, sensível e estética da pessoa como forma de dimensionar a valorização da contemplação sensível do mundo enquanto aspecto determinante para a consideração dos desejos e da construção do conhecimento de si. Portanto, a proposição deste conceito foge à linearidade e ao engessamento do saber estético.

Ao pensar a estética como saber sensível, um conhecimento que perpassa o sentir, em oposição à estética transcendental de Kant (2015), observamos o belo não em sua conotação usual, mas como aquilo que é capaz de ecoar sensível e esteticamente na pessoa. Não é aquilo julgado como 'portador' de beleza, mas a experiência estética em si como elemento mediador entre a alma, a subjetividade e o que se entende como belo.

Com base nos pressupostos destacados, as nuances sobre a pedagogia do belo contemplam uma educação pelo sensível. No estudo é assumida o seguinte problema de pesquisa: é possível cogitar algumas premissas à Pedagogia do Belo a partir das sensibilidades? Assim, o objetivo geral do presente estudo é refletir sobre as contribuições da pedagogia do belo para o pensamento pedagógico pautado nas sensibilidades. Propomos, desse modo, os seguintes objetivos específicos: conjeturar sobre a relação entre a educação estética, a pessoa e suas subjetividades; problematizar a arte enquanto elemento mediador entre a subjetividade e a exterioridade; e, por fim, apresentar o conceito de pedagogia do belo enquanto categoria teórica.

\section{Encontros em estética: a pessoa e o belo}

A dimensão estética explica as coisas sem que seja necessário evocar a materialidade do mundo. Trata-se de um saber que opera a partir dos princípios da sensibilidade. A sensibilidade, para Kant, é considerada como a “[...] receptividade de nossa mente para receber representações, na medida em que ela é afetada de algum modo [...]” (KANT, 2015, p. 96). Ou seja, a capacidade pela qual é possível alcançar representações ou ser afetado por objetos externos.

A sensibilidade conduziria a sensações decorrentes da influência organizada do objeto sobre a pessoa, apenas. Suscita comportamentos e, ainda, leva ao que se considera o 'conhecimento' sobre as coisas ou dado fenômeno. Ao intuir, no campo do empírico, formarse-ia um elo automático entre o pensamento e o conhecimento. O entendimento, então, é assumido apenas como uma faculdade capaz de produzir representações imediatas. Conduz a representações, reflete sobre elas e constrói conceitos. É, nestes termos, que opera a 'espontaneidade' do conhecimento em Kant (2015). 
Diferentemente, a intuição é o disparador que age no campo do sensível e, então, conduz ao conhecimento (CARDOSO; GOMES; CARVALHO, 2019). Maffesoli (1998, p. 130), por sua vez, com base na psicologia junguiana, concebe esta noção como sendo "[...] oriunda de um tipo de sedimentação da experiência ancestral, que ela exprime o que podemos chamar de ‘saber incorporado' [...]”. De tal modo, enquanto sensibilidade intelectual, é capaz de se antecipar ao mero saber racional e permitir o múltiplo de forma orgânica.

A vivência da experiência estética é o universo que propicia mais do que previu a razão kantiana. Pois, nela a subjetividade interliga-se ao gosto e juntos são capazes de favorecer uma moralidade outra, à medida que evitam a determinação lógica da vontade, como menciona Barbosa (2004). É a vontade, quando expressada livremente, que evidencia o que Schiller (2017, p. 98) dispõe como "liberdade física", distinta da "liberdade moral". Esta última se expressa como um tipo de anseio que está associado à prudência, que não é refém da vontade em si, como na primeira noção, mas que a reflete de modo sensível para que a sua concretude não interfira negativamente na vida.

A busca pela liberdade moral se insere na contemplação e na vivência estética. Tem o gosto como característica e é capaz de moldar certos impulsos das pessoas (GOMES; CARVALHO, 2018). A partir de tal capacidade de discernimento floresce sensivelmente (e não racionalmente, como previu Kant) a vontade livre. Segundo Barbosa (2005), a capacidade de captar as nuances do belo na perspectiva do ato/potência, fundamentado em Schiller, é um divisor de águas neste debate. A perspectiva shilleriana aduz ao belo enquanto liberdade estética. É por meio da referida definição que a relação entre a pessoa e a sensibilidade se recompõe frente às vontades racionais e vazias de sentido.

No entanto, o conceito de gosto surge não apenas como uma categoria associada à moral, como sugere o pensamento kantiano. É também um juízo com base no qual a reflexão estética livre é fundada e pelo qual se afasta do senso meramente empírico-racional. Logo, não tem fundamento somente em conceitos, como previu Kant (2015), mas acontece a partir da síntese entre sensibilidade e entendimento, promovida pela imaginação.

Por esse motivo, a arte é o elemento que contribui para que a cultura estética favoreça o acesso da natureza humana à sua plenitude (CARVALHO; GOMES, 2019). Pois, enquanto seres sensíveis, as pessoas são afetadas pelo que existe ao seu redor e tais afetos podem dar forma a uma razão sensível (BARBOSA, 2004). Assim, por meio da cultura estética, a pessoa alcança maior liberdade e torna-se mais humana (SÜSSEKIND, 2011).

A educação estética se consolida na sensibilidade do ser. Reconhece "[...] a importância dos sentidos nos quais a consciência, a inteligência e o julgamento do indivíduo humano estão 
baseados" (SOARES, 2015, p. 41-42). É um processo no qual a condição técnica e racional é transcendida por meio do apelo ao estético. Remete à intermediação do belo na arte, que é capaz de potencializar o pensamento e trabalhar na construção da reorganização da pessoa internamente, faz alcançar uma consciência de si (READ, 2001).

A arte é feita por pessoas e para pessoas, um campo formado pelas subjetividades, pois as marcas deixadas pela vida do(a) artista afloram tanto na produção quanto na contemplação de uma obra (GOMES, 2019). A subjetividade potencializada permite viver com arte e sentir a partir do que o estritamente racional não permite, ou seja, que pulsa em cada pessoa pela sensibilidade e pelo estado de liberdade vivido no momento. Afinal, a sensibilidade como elemento central da pedagogia do belo não decorre de normas meramente condutoras, escapa do alcance das imposições da racionalidade que ambiciona controlar e normatizar a forma como se pensa. Consegue ser transgressora e insurgente sem ser impositiva (GOMES; CARVALHO, 2018).

Olhar uma obra de arte, principalmente no que concerne à arte abstrata ou conceitual, ajuda a compreender o sentido da sensibilidade e das subjetividades no estudo da estética. Pois, ao ver e sentir o que a plasticidade apresenta, vive-se uma experiência particular. Entretanto, o que pulsa e faz cada pessoa pensar sobre a obra depende de suas experiências, da profundidade com que se afeta.

O reconhecimento da pessoa como inacabada é o primeiro passo para que se perceba a singularidade deste movimento. Esta premissa surge no pensamento de Schiller (2018), quando o autor menciona sobre a pessoa e os seus estados, demostrando que existimos em duas dimensões ao mesmo tempo: a partir da essência que temos a todo tempo e o nosso estado, o qual é volátil, molda-se a cada instante seguindo as interações que são estabelecidas com e no mundo. Tal possibilidade de constante troca de 'estados' funda a noção de subjetividade, contrapõe o projeto de ser humano universal, uma suposta forma única de existir que marca a racionalidade kantiana, por exemplo. Assim, tem-se que:

\footnotetext{
Uma necessidade fora de nós determina nosso estado e nossa existência no tempo através da impressão sensível. Esta é inteiramente involuntária, recebemo-la passivamente segundo a maneira pela qual somos afetados. Da mesma forma uma necessidade em nós revela nossa personalidade por ocasião daquela impressão sensível e por oposição a ela; pois a autoconsciência não pode depender da vontade, que a pressupõe. (SCHILLER, 2018, p. 94, grifos do autor).
}

Portanto, não se trata da interpretação errônea sobre as subjetividades, aquela que é assegurada para manter o sistema hegemônico-moderno do saber e que confunde singularidade com individualismo. Pode-se ver traços no outro que nos dão forma, uns que se tem prazer em revelar, outros nem tanto. Desenhados por diferentes aspectos, a nossa multiplicidade precisa 
ser observada, pois é a falta de conhecimento do que se é que suscita as dificuldades de viver e de conviver.

No reconhecimento do estado de decadência humana é que se procura o reconhecimento interior, motivado pela busca de superar o que se é quando não se agrada da própria existência. Isso é perceptível nos textos de Nietzsche, quando o autor percebe o ser humano como um "animal ainda não determinado" (NIETZSCHE, 2004, p. 72) e, ainda, como possível de ser superado, como implícito em alguns prólogos de Zaratustra. Nietzsche (2004) discorda da noção de um "eu" fixo e ressalta a subjetividade enquanto o fluxo de transformação que possibilitará a superação da condição de decadência humana e para a ascensão do cuidado de si e do outro.

Ao acatar o estado de passividade e obediência requerido pela modernidade- retratado na imagem do camelo, na filosofia nietzschiana -, discute-se que as pessoas perderam a humanidade, decaindo o seu espírito criativo e a sua personalidade. Em oposição a tal imagem, aposta-se em uma consciência de se colocar acima das ordens ditadas, de deixar a personalidade se sobressair - a natureza não mais do camelo mais sim do leão. Uma vez que este é o primeiro passo na busca para transcender o estado de dominação em que a pessoa se encontra. Uma mudança capaz de levar ao encontro do Übermensch, um estado de completa noção de sua humanidade, onde se consegue estabelecer seus próprios julgamentos éticos de modo natural, de existir além das limitações que a sociedade moderna possa nos induzir.

A hermenêutica de tal 'modelo ideal' apresenta uma eterna sensação de "vir a ser", porque é assim que Nietzsche (2018) assume a grandiosidade de ser passagem, uma ponte, não um fim. É a possível transição que não permite que exemplos históricos materializem a existência humana. Então, o que se vê é uma série de personagens em que as pessoas podem revelar-se ao longo da vida, a depender de como se conhecem e que se colocam passivas de influências. Pois: "Eu só amo aqueles que sabem viver como se extinguindo, porque são esses os que atravessam de um para outro lado" (NIETZSCHE, 2018, p. 17). Na ponte que leva de um lado ao outro e que permite se autoconhecer, extinguir aquilo que não faz sentido ser.

Em diálogo com o pensamento maffesoliano, assimila-se a ideia de não haver uma condição de existir como um perfil seguro, que faça passar de um ser vazio para a ideia de pessoa, plena, acomodada na estabilidade dos modos de ser de um mesmo eu. O eu incerto e flutuante tem sua existência questionada por tal premissa, o quem sou eu torna-se algo fluido. Existe, assim, uma passagem da identidade formada e defendida na modernidade para uma identificação, considerada como o mito da pós-modernidade, o qual tem como característica não a mesmidade, mas a repetição (MAFFESOLI, 1996). 
O sentimento de "mudança de pele" ou uma "esquizofrenia diária" que Maffesoli (1996) apresenta para explicar a multiplicidade de personagens que podemos desempenhar ao longo da existência são bem-vindos ao debate. Esses conceitos sugerem a dissolução da ideia de identidade, pois, enquanto fechada, não permite que haja o intercâmbio entre o mundo ao redor e o modo de ser das pessoas. Outrossim, as subjetividades têm se construído conforme nos identificamos com aspectos presentes na vida social e nos re-fazemos, repetindo-os. Uma experiência múltipla e, ao mesmo tempo, única de ser, que permite fazer-se ao longo das experiências vividas.

Desse modo, o $e u$ não se constrói apenas na interação com os objetos presentes no mundo, mas também com as outras pessoas. Em um espaço de inter-relações e trocas mútuas, cada pessoa desenvolve suas subjetividades a partir das sensibilidades pelas quais é afetada. Assim, cada pessoa deve ser levada em conta como um ser "compósito e complexo" (MAFFESOLI, 1996), que se forma por diferentes e incontáveis experiências e de exercícios reflexivos e morais, que desenvolve sua autoconsciência, afastando-se do individualismo e vivendo a partir da conciliação dos desejos particulares com os desejos da comunidade.

O modo como é banalizado o que o outro sente faz com que as trocas não sejam tão intensas, uma vez que não se leva em consideração o que cada um é e seu trajeto antropológico. Pois, a pessoa é aberta às influências que recebe da vida social e por elas constitui-se, sendo sua imaginação resultado dos sentimentos e afetos experienciados ao interagir com o mundo (CARDOSO; GOMES; CARVALHO, 2019).

Foucault (2006), por exemplo, discute a partir dos diálogos entre Sócrates e Alcibíades a busca pelo conhecimento sobre si mesmo, sobre conhecer-se para assim deixar fluir a existência do que se é, e de modo a não se inclinar ao que pode fazer mal. Tal processo é narrado enquanto contínuo e confuso, mas que traz bons resultados, pois, como citou Nietzsche: “[...] é preciso ter um caos dentro de si para poder dá à luz uma estrela cintilante" (2018, p. 21). Afinal, a potencialidade humana não é algo que se faz presente apenas na racionalidade, é uma conversa entre duas pessoas, o encontro de sentimentos, de afetos e de memórias (CARVALHO; GOMES, 2019). Não se trata de uma relação regida pelo egoísmo, como retratado no mito narcísico, na existência de um $e u$ acima do outro, é, na verdade, uma exímia beleza, um ego ampliado que permite compreender a plenitude da realidade.

Portanto, existir no mundo é algo dinâmico e que produz significações singulares sobre os objetos e fenômenos. Aporta na consideração de que não existem verdades únicas a serem seguidas universalmente. A fuga à rigorosa racionalidade está presente nas consciências criativas e produtivas, reprimidas pela proposta de uma identidade homogênea. Afinal, ao longo 
do tempo, o pensamento ocidental, de base racionalista, limitou a importância das subjetividades para a construção do saber, deixando-as reservadas ao trabalhado na arte, considerado menor, assim como metaforizou Nietzsche: "A luz das estrelas mais longínquas chega mais tarde até nós e tanto que o homem que não as percebeu nega a sua existência." (2004, p. 218).

\section{A arte enquanto potência educativa: sobre a compreensão do mundo fora de si}

De acordo com Martins, Picosque e Guerra (1998, p. 61) a arte “[...] transcende o tempo e transpõe fronteiras”. O fato de encontrar na arte partes do nós, faz com que este campo não envelheça. E ressaltam que: “[...] o ser humano que a contempla é sempre novo, ou terá um olhar outro e estará realizando uma infinidade de leituras porque infinita é a capacidade do homem de perceber, sentir, pensar, imaginar, emocionar-se e construir significações diante das formas artísticas”. (MARTINS; PICOSQUE; GUERRA, 1998, p. 61). A arte permite cogitar dimensões outras da existência que a racionalidade despreza. Inaugura um campo aberto aos sentidos.

Assim, viver com arte, falar de arte e educar a partir da arte é agir contra o projeto hegemônico (e homogeneizante) da modernidade. Tal movimento insurgente não segue o entendimento incutido sobre identidades fixas, tem por base a subjetividade revelada e exaltada, a partir da heterogeneidade, a autêntica marca da contemporaneidade. O potencial da arte suscita questionamentos e permite sensibilizar pela linguagem poética e metafórica.

A arte é " [...] transgressora, contundente e incisiva. Enriquece-nos se nos permitimos pensar sobre ela, ampliando nossas próprias referências, para além de fatos e de relações habitualmente esperadas". (MARTINS; PICOSQUE; GUERRA, 1998, p. 26). A "razão sensível" (MAFFESOLI, 1998), empregada no trato com a arte é fundamental, também, para pensar os problemas contemporâneos: preconceitos, racismo, machismo, LGBTfobia, etc. Desta maneira, “O problema principal da arte do nosso tempo, em que estala por todas as juntas a armadura do capitalismo, é criar uma ponte nova entre o povo e o artista - e por povo entendase todo o mundo, todos os não artistas.” (CALLADO, 1976, p. 9).

Para Duarte Júnior (2000), a arte se apresenta como um precioso instrumento para pensar a educação do e pelo sensível, capaz de suscitar inusitadas maneiras de sentir e perceber o mundo. A partir dela, a realidade vivida pode ser questionada e (re)significada. É possível aprender sobre si mesmo, sobre o mundo e sobre como relacionar os saberes advindos da experiência estética. 
Partindo da arte, a estética possibilita a formação do olhar das pessoas, é uma passagem sem volta de um lugar enclausurado para uma perspectiva plural, pois reconcilia as principais esferas da existência: a sensibilidade e a razão. O desenvolvimento da sensibilidade possibilita às pessoas o despertar para uma melhor aplicação do conhecimento em suas vivências. Surge uma visão de mundo mais ampla e diversa, capaz de suscitar ideias que, organicamente, organizarão o olhar.

Existe um elo histórico entre as pessoas e a arte, o qual sustenta a própria natureza social da mesma, que metaforiza e reflete características de determinado grupo, fenômeno ou momento social. Na contemporaneidade, é um dispositivo que funciona como um estímulo para sentir todas as vibrações, permitindo, poeticamente, um sentimento de unidade entre todas as criações. A arte compactua do princípio do "vitalismo", ao qual se refere Maffesoli (1998, p. 45). Acontece em aliança com as questões políticas, sociais e culturais, lembrando a todo momento que existe um cotidiano repleto de experiências sensíveis, no qual a "sensação, compreendida num conjunto, é fator de relação social" (MAFFESOLI, 1996, p. 86). Nesse sentido, a arte concebe os fatos sociais com e em liberdade, enquanto espelho que revela à sociedade aquilo que a vagueza do olhar não enxerga. Quem 'lê' a arte são os 'olhos da alma'. Nessa perspectiva, Ernst Fischer (1976, p. 13) afirma que: “A arte é o meio indispensável para essa união do indivíduo como o todo; reflete a infinita capacidade humana para a associação, para circulação de experiências e ideias". É uma significação coletiva.

A arte permite que a sensibilidade e a imaginação sejam exploradas. Possibilita o encontro com o ato de conhecer a partir da poética e da subjetividade. Por ser a representação do sentir e do viver, apresenta significados outros. Essas formas são encontradas e criadas $a$ partir do e para o encontro entre a pessoa e o mundo. Acontecem a partir do momento no qual se nutre simbolicamente e sensivelmente a pessoa. Advém, então, do poder de síntese presente na linguagem da arte (MARTINS; PICOSQUE; GUERRA, 1998).

A arte possibilita, igualmente, a expressão do que somos. Traduz-se num processo formativo que existe pelo fato de ser, antes, uma prática política; uma prática capaz de desenvolver o olhar e de, simultaneamente, mantê-lo sempre em construção. É a constante necessidade da arte. Enquanto combustível para a vida, configura-se também como um processo de catarse que permite nutrir a alma, a vocação e a festa, como sugeriu Ariano Suassuna (2012).

Então, de que modo a arte pode educar e intervir na realização da vida moral da pessoa? Nesse trajeto, Schiller (2017) menciona o impulso lúdico. A arte permite religar a bifurcação que se criou entre o sensível e a razão. De tal modo, o sensível opera como o ponto de equilíbrio entre o pensamento e o impulso formal. Os sentidos capturam elementos das vivências que não 
eram possíveis de se perceber racionalmente. Forma-se, então, a relação entre a estética e a ética, na qual o gosto atua ativamente e de modo decisivo nas vivências, sendo cultivado e (re)significado. Podemos perceber que a pedagogia para o viver estético-ético parte de influências simbólicas. Assim,

\begin{abstract}
A formação do gosto é entendida no todo como uma contribuição para o cultivo da humanidade. A autonomização da estética não é só para a estética, mas para além, em favor de um projeto pedagógico e político de autonomização da humanidade significativo no todo. Ela exige o progresso da cultura na totalidade. Nisso situa-se, para Kant, uma tarefa da estética e, no extremo, a base de legitimação de sua autonomização. (HERMANN, 2005, p. 33).
\end{abstract}

O gosto possibilita a formação humana. Ao se permitir ver o mundo sob uma perspectiva sensível, a educação estética passa a ter preponderância na vida. Cada desconforto e estranhamento que afeta a pessoa intimamente é uma descarga de sensações que arrepiam os pelos (ARAÚJO, 2009). Assim, na arte é possível deixar se afetar por várias sensações e emoções que surgem com a liberdade que é dada ao ato de criar, espaço que o conhecimento é potencializado em cada $e u$. O diferente é conhecido e assim se atribui outras representações às pessoas e aos fatos. Desse modo, “a estética tem se mostrado hábil [...] evidenciando aquilo que é estranho, uma liberdade do sensível contra o embrutecimento da percepção automatizada." (HERMANN, 2011, p. 440).

É preciso apreciar e sentir a arte. A ideia de simplesmente entender escapa à dimensão sensível e recai naquilo que é meramente inteligível. É nesse contexto que a educação e o aprimoramento dos sentidos demonstram importância. A percepção é a chave das trocas que a arte e o observador realizam. Tal percepção ressalta que a não consideração dos sentidos de modo permanente ao longo da vida se desenvolveu, de certo modo, como o medo de sentir e, portanto, recorre-se principalmente ao mero assimilar. Tal postura reduz a dimensão imagética e simbólica da arte a uma racionalização dicotômica, sempre fechada ao diferente e nunca disposta a explorá-la. Este preceito nega a intersecção entre a arte e o mundo porque, à medida que é racionalizada, “[...] a experiência estética perde a força de ser um contraponto às convenções do cotidiano e às certezas confiáveis" (HERMANN, 2011, p. 441).

Portanto, a leitura do mundo pela arte agencia outras temporalidades. É um processo contínuo de trocas no qual os objetos e as pessoas se afastam da definição exata da realidade. Logo, passa a ser uma realidade sempre mediada, que torna múltiplo o processo de percepção com base nas intuições que re-visitam o imaginário (CARVALHO; CARDOSO, 2015). A realidade é, então, apresentada enquanto uma troca de sensações, motivo pelo qual "a estética tem se mostrado hábil na experiência da alteridade" (HERMANN, 2011, p. 440). Eis que a estética se aproxima da antropofagia exaltada na Arte Moderna. Um conhecimento decorrente 
do 'digerir' o objeto, de transformações na realidade; faz uso da natureza criativa que pela a percepção das coisas, interpreta e cria sentidos outros, cíclica e simultaneamente.

\section{Por uma pedagogia do belo: notas para uma introdução}

Ninguém educa ninguém, educamo-nos entre nós mesmos, sob a mediação do mundo, assim como referiu Paulo Freire (1987). Com base nesse pressuposto, argumentamos que o mundo da arte media, sensível e simbolicamente, o conhecimento. A partir de Schiller (2017) e Maffesoli $(1996 ; 1998)$ as reflexões sobre tal hipótese mobilizam, igualmente, os sentidos e significados sobre o significado do belo. Schiller (2017), por exemplo, articulou a arte como pressuposto para a educação, devido a sua estimulação potente da contemplação do belo. Maffesoli (1998) contribuiu com a proposição de que são as subjetividades que sustentam a relação entre as pessoas e o conhecimento. Argumentamos, então, que é instituído um diálogo entre a pessoa e a obra de arte que ultrapassa a mera contemplação. Trata-se do deleite, do gesto que transporta o momento em que a pessoa reflete sobre os sentimentos que lhe são suscitados pela obra para a vida; são as suas memórias, afetos e subjetividades que passam a operar enquanto uma pedagogia mediada pelo belo.

Assim, a releitura da obra destes autores, sobretudo, e de outros(as) inspira e fundamenta o ensaio de uma categoria teórica para pensar a educação estética, a qual denominamos de pedagogia do belo. Trata-se de uma concepção estético-formativa que é pautada no processo de cuidado da natureza mista das pessoas, que auxilia o desenvolvimento de sentidos e de significados que guiam não apenas a observação, mas também a ação das pessoas no mundo. Falamos de uma pedagogia que desloca o ato de compreender da dimensão meramente intelectual para o corpo e as suas experiências. Nesta compreensão, que é corporal e afetiva, o sentir se une à memória e à imaginação, agencia valores outros que conferem significado à experiência estética e humana.

As pessoas são criadoras de símbolos. Assim, Martins, Picosque e Guerra articulam que: "[...] quando um homem quer falar ao coração dos outros homens ele o faz pela linguagem da arte.” (1998, p. 5). Tal como dispõe Larrosa (2006) sobre o potencial poético do escritor e suas obras e acerca da finalidade da escrita. Pois, para o autor, é possível traçar um paralelo entre o escritor e o artista, afinal a transmissão do silêncio quando se lê uma imagem atualiza os sentimentos e pensamentos que já nos tocaram outrora. É algo ligado ao mágico, ao encontro do $e u$ atual com o seu outro passado, um diálogo em si mesmo. 
A linguagem da arte, por ser aberta ao mundo e permitir a liberdade de realizar trocas com a realidade, é uma viagem pelo sentir com destino certo: a experiência, característica que lhe confere potencial formativo capaz de dimensionar a pluralidade da existência humana. É nessa abertura ao mundo, e por meio das trocas, que a arte educa. Surge enquanto um processo no qual “[...] não posso pensar pelos outros nem para os outros, nem sem os outros. A investigação do pensar do povo não pode ser feita sem o povo, mas com ele, como sujeito de seu pensar." (FREIRE, 1987, p. 101). Deste modo, o potencial educativo da arte ressalta o pensamento de Paulo Freire de que “[...] ninguém educa ninguém, como tampouco ninguém se educa a si mesmo: os homens se educam em comunhão, mediatizados pelo mundo. Mediatizados pelos objetos cognoscíveis." (1987, p. 68). Ao sentir o valor simbólico que os objetos sensíveis possuem é possível questionar o que está posto.

$\mathrm{Na}$ pedagogia do belo o pensamento de vontade e de reconhecimento proposto por Schopenhauer (2005) aduz ao momento no qual a consciência se afasta do condicionamento racionalista do olhar e se perde na contemplação do mundo e da obra. A pessoa transita pelo que intui, tão-somente. Quem observa passa a existir de maneira conjugada ao objeto, a consciência é preenchida pelas relações de troca e percepções que se deixa experimentar. Nesse processo de viver à deriva, as experiências estéticas evocam novas compreensões. São uma organização outra do imaginário que se constrói conforme os pensamentos sobre a realidade surgem, por meio de constantes e cíclicos questionamentos.

Assim, o belo torna-se uma mediação poética de forças que perpassam a pessoa. A partir de sua subjetividade, admite a alteridade. Observador e objeto contemplado se preenchem reciprocamente. Neste 'desaparecimento' da pessoa frente ao objeto está a liberdade. Para Schopenhauer (2005), o ser atua libertamente quando se desprende da visão comum condicionada pelo mundo exterior. Ao referido processo, o autor atribui o surgimento de "puro sujeito do conhecimento". Sobre esta noção, Rolnik (2011, p. 3), comina à referida representação a

[...] capacidade de se deixar afetar pelas forças que agitam os objetos criados pelo artista, bem como o ambiente em que esses objetos eram vividos, sob a ilusória estabilidade de suas formas, apreendidas pela percepção. A obra se completava com a ativação de sua vulnerabilidade à sensação da disparidade entre os dois exercícios paradoxais da cognição - a percepção das formas do mundo e a vibratibilidade às forças que o animam - quando sua tensão atinge um limiar. $\mathrm{O}$ desafio era que $\mathrm{o}$ receptor pudesse sustentar-se no "vazio pleno" do espaço de alteridade que tais forças abriam em sua subjetividade: um vazio de sentido, pleno de sensações de seus movimentos conturbados o layout de si e do mundo e fazendo pressão para reinventálo. 
Segundo Schiller (2017, p. 119), o contemplar “[...] é a primeira relação liberal do homem com o mundo que o circunda". A partir dele, a pessoa se coloca fora de si e, assim, insere-se em um estado estético no qual a personalidade é ressignificada. Na pedagogia do belo o sensível e o racional se interseccionam a partir da contemplação, permitindo que os sentidos conduzam à poética do ato de conhecer. É o momento em que o tempo é paralisado e o eu se perde nele. $\mathrm{O}$ agora assume, então, o contato com a beleza, contemplação pela qual “[...] o pensamento toca a sensação interna e a representação da unidade lógica ou moral converte-se num sentimento de harmonia sensível" (SCHILLER, 2017, p. 120-121). O conhecimento conduzido por meio da pedagogia do belo é diverso e ligado ao outro.

A pedagogia do belo conduz a uma reestruturação do consciente que acontece e assente ao imaginário (CARVALHO; CARDOSO, 2015). A imagem torna-se o instrumento mediador não apenas das subjetividades, mas também do próprio conhecimento. Não se trata da imagem material, que é absorvida com os olhos, apenas, mas da imagem que se forma sobretudo pelo que sentimos e intuímos na mediação proposta pela e com a arte. Afinal, como sugeriu Jung (1932), a imagem está diretamente ligada à autoconstrução da psiquê; interfere no imaginário humano, no modo como as relações com a realidade são estabelecidas e na maneira como o mundo é compreendido e os pensamentos produzidos.

A imagem é capaz de lançar a pessoa em um universo no qual o conhecimento é encontrado por meio das experiências, tendo a razão igual importância em relação aos sentidos. Afasta a base racional que induz à compreensão dos fenômenos de maneira estática, apresenta, diferentemente, uma infinidade de percepções. Ao considerar o 'viver estético', as linguagens artísticas e poéticas passam a ter significado, tornam-se, pelo imaginário, uma janela para a ligação entre o corpo e o espírito, as sensibilidades e as subjetividades.

Segundo Durand (2012, p. 18), o imaginário articula a produção e a reprodução de imagens, mitos, símbolos e arquétipos pelo ser humano, é “[ [...] o conjunto das imagens e das relações de imagens que constitui o capital pensado do homo sapiens [...]”. Considera as mediações simbólicas que são reforçadas na relação com a realidade e a sensação de necessidade delas. Na pedagogia do belo, o saber elaborado com a contribuição do imaginário está articulado à forma como a pessoa interpreta os símbolos com quais se relaciona, o deixarse-afetar. Afinal: “o imaginário não só se manifestou como atividade que transforma o mundo, como imaginação criadora, mas, sobretudo, como transformação eufêmica da realidade, como intellectus sanctus, ordenança do ser às ordens do melhor” (DURAND, 2012, p. 432).

$\mathrm{O}$ arcabouço que sustenta nosso imaginário - schèmes, arquétipos, símbolos e mitos opera de modo sincronizado para envolver simultaneamente o conjunto de emoções da vida, 
fazendo com que as experiências com as quais a pessoa se envolve sejam o ponto de partida para alcançar a "iluminação pelos sentidos"(MAFFESOLI, 1998). Neste jogo os símbolos contemplados conseguem trazer para o consciente os significados presentes em nossa memória e no imaginário, intuitiva e pedagogicamente. A arte media o referido processo, pois, os artistas percebem o mundo e o metaforizam nas obras de arte. Deste modo, a sensibilidade estabelece a relação entre o que está a nossa frente, a subjetividade e os processos históricos. (CARDOSO; GOMES; CARVALHO, 2019).

As obras de arte, em seus enigmas, produzem saberes que não podem ser desconsiderados. A presença do simbolismo conduz a um sentimento de ajuntamento, no coletivo, que acontece a partir do conhecimento sensível e dos afetos comuns. Portanto,

\begin{abstract}
a arte não altera tão somente o humor dos indivíduos, mas é capaz de objetivar sentimentos humanos e demais potencialidades. Sendo assim, altera o psiquismo dos sujeitos, propiciando uma reorganização psíquica e a elevação da condição de indivíduo singular à humanidade enquanto gênero universal. Ela funciona como mediadora do individual e do gênero humano por se tratar de uma síntese do que existe de biológico e de cultural, constituindo-se das características humanas mais complexas referidas, que foram construídas historicamente, ou seja, por meio do trabalho (WILLMS; ALMEIDA; BECCARI, 2019, p. 104).
\end{abstract}

Enquanto registro atemporal, a arte é capaz de interligar o passado e o presente, contribuindo com a reconstrução coerente de um sentimento de identificação com as experiências retratadas no simbolismo de cada artista. Consente que olhares outros sejam lançados sobre a realidade; colabora com a valorização e formação de memórias contrárias à razão que busca, tão-somente, construir uma identidade homogênea que desconhece a pluralidade dos povos e, por vezes, invisibiliza suas experiências.

No exercício da pedagogia do belo, a obra de arte opera como um artefato, uma metáfora que “[...] não traz respostas, mas provoca em nós uma profusão de perguntas que nos faz extrair delas novos, diferentes e mais profundos significados do que o nosso olhar contaminado pelo cotidiano vê sobre nos mesmos, o mundo ou as coisas do mundo." (MARTINS; PICOSQUE; GUERRA, 1998, p. 44). Tratamos, então, de dar vez a uma pedagogia que tem a arte como “[...] o grande estimulante de viver; como se poderia entendê-la sem finalidade, sem alvo, como l'art pour l'art" (NIETZSCHE, 1988 apud HERMANN, 2005, p. 56).

A atuação da imaginação no momento de deleite e o sentimento de transcendência tornam-se elementos centrais para pensar a pedagogia do belo. No primeiro aspecto, cria-se e recria-se imagens sobre os fenômenos a nossa volta e, no segundo, à medida que o belo conduz a pessoa da sensação ao pensamento, desperta ideias sobre suas próprias subjetividades. 
(Re)significado a partir da imaginação, o belo forja uma reflexão recíproca e uma íntima relação sobre a intuição e o entendimento, sendo as obras de arte um referencial para mobilizar a capacidade e a atividade imaginante das pessoas. As linhas que dão forma a cada representação simbólica constroem diferentes domínios, sob os quais a imaginação se ocupa em ressignificar. Os símbolos estabelecem uma ligação entre a presença no espaço/matéria, que é a obra e a subjetividade da pessoa que a observa (BENJAMIN, 2017). Tal mediação, de caráter subjetivo entre a pessoa e o símbolo, releva o pressuposto a partir do qual Schiller (2018) afirma que o belo recai sobre a imaginação e o entendimento. Assim, a imaginação permite que as experiências sejam ampliadas, pois é do real que os significados sobre os quais elas atuam são retirados.

O sentir transcendente reafirma que, ao estimular o belo, a arte amplia a reflexão e auxilia a pessoa a constituir os seus juízos. A atividade da consciência é primordial para alcançar a liberdade e refinar o olhar. Por meio da pedagogia do belo cogita-se um saber sobre e a partir de si mesmo. Neste sentido, ao se pensar em transcendência, como proposto por Nietzsche (2004), é articulada uma mudança não para algo além do ser humano, metafisicamente superior, mas a possibilidade de transformação do próprio estado de espírito. Trata-se de uma ascensão a um $e u$ elevado em si, livre a partir encontro com o sentido da vida mesma.

Tais mudanças não acontecem na dimensão da mera racionalidade, pois apenas são sentidas e desenvolvidas a nível do simbólico. Ponto fundamental para que o belo se faça presente no processo de acesso a uma condição humana outra, modificada por meio das experiências, é o fato de que tal gosto permite à educação estética cultivar as pessoas com base na mediação criadora de si e do mundo.

A atuação da imaginação tem papel importante na reflexão sobre a liberdade, pois ela é o núcleo que capacita inventivamente as pessoas. Afinal, é no deleite que o ser humano se desenvolve eticamente (SCHILLER, 2018). O ato de imaginar habilita o sensível ao conjeturar os estímulos que a obra aduz. Constrói-se, portanto, uma lógica do coração, que não é refém da coerência racional sobre as coisas, mas sim uma razão sensível, tal como sugere Maffesoli (1998).

Ao interseccionar a arte e a educação estética, a pedagogia do belo articula aspectos fundantes sobre as sensibilidades no fruir da existência e permite a exploração das subjetividades. É uma maneira de diversificar o conhecimento que surge e é intermediado pela arte, a partir do imaginário. Relaciona-se ao que Maffesoli (1998, p. 187) denomina de “iluminação pelos sentidos”, uma forma de perceber o conhecimento e de apreender o mundo 
de maneira afastada da mera racionalidade. Considera, dessa maneira, o equilíbrio entre os impulsos sensíveis e formais aos quais Schiller (2017) vincula-se fortemente ao problematizar a natureza humana.

A pedagogia do belo é inspirada no entendimento do 'belo' enquanto ação poética. Afinal, segundo Schiller (2017), há muito o que se pensar e perceber no diálogo entre as pessoas e os objetos sensíveis. Esta categoria teórica é assumida enquanto a participação da imaginação que busca encontrar sentido para os signos percebidos na e a partir da obra de arte. Pois, ressalta que: "O belo é o caminho que leva o homem da sensação até o pensamento" (SCHILLER, 2017, p. 92). Assim como Schiller (2017), Maffesoli (1998) agrega sentido à razão sensível que dimensiona o conceito mencionado. Faz pensar a estética como uma experiência mediadora, que acontece ao viver e experimentar o mundo, na qual o cotidiano possui força mobilizadora das sensações que atuam sobre a imaginação e o olhar.

Portanto, a pedagogia do belo é uma categoria teórica que compreende a educação estética numa dimensão mais ampla, para além do gosto kantiano. Traduz-se em uma atividade que acontece no contexto sociocultural no qual a pessoa se insere, nas mediações com a arte que proporcionam o desenvolvimento de sentidos e de valores que repercutem entre o que é sentido, vivido e exercido. Esta categoria abarca o transcender de um estado anestésico para formação de uma postura estético-ética de ver e estar no mundo. Uma proposta estéticoformativa constituída com base nas trocas e afetos e por meio da contemplação sensível de elementos simbólicos.

\section{Considerações finais}

É possível encontrar na arte um caminho sensível e capaz de educar as pessoas. Por isso, as reflexões (iniciais) sobre a pedagogia do belo aduzem à valorização das sensibilidades. Distancia-se da perspectiva formativa pautada na lógica racional do conhecimento. A arte permite, então, a abertura ao trabalho com elementos subjetivos, seja em relação a visões de mundo ou o que pode ser suscitado. É uma fresta que se alarga para pensar a relação entre o eu e o outro a partir das trocas sensíveis.

A potência da pedagogia do belo para explorar os modos como o conhecimento pode ser construído a partir da arte, demonstra um caminho no qual o ato de conhecer tem fundamento no diálogo entre a pessoa e a ética. Tal argumentação pedagógica coloca em rediscussão o modo como a imaginação é atuante no processo formativo, no qual a intuição 
junta-se à razão sensível para, então, significar o que a experiência estética é capaz de apresentar e apreender.

Trata-se, portanto, de um ensaio sobre a referida categoria teórica. Assume-se o devir que a potência do belo envolve quando se trata do sentir e da possibilidade de se reconhecer a exploração da capacidade sensível do mundo e de si. A pedagogia do belo é tomada como uma categoria teórica, parte da educação estética, eticamente comprometida com as sensibilidades e as subjetividades, com base na qual as experiências equacionam outra lógica de pensamento.

\section{Referências}

ARAÚJO, Miguel Almir Lima de. Os sentidos da sensibilidade e sua fruição no fenômeno educar. Educação em Revista. Belo Horizonte. v. 25, n. 02, p. 199-222, ago., 2009.

Disponível em: http://www.scielo.br/pdf/edur/v25n2/09.pdf Acesso em: 15 jan. 2020.

BARBOSA, Ricardo. A especificidade do estético e a razão prática em Schiller. Kriterion. Belo Horizonte, n. 112, p. 229-242, dez, 2005. Disponível em:

http://www.scielo.br/pdf/kr/v46n112/v46n112a08.pdf. Acesso em: 15 jan. 2020.

BARBOSA, Ricardo. Schiller \& a cultura estética. Rio de Janeiro: Jorge Zahar, 2004.

BENJAMIN, Walter. Estética e sociologia da arte. Tradução de João Barreto. Belo Horizonte: Autêntica, 2017.

CALLADO, Antonio. Introdução. In: FISCHER, E. A necessidade da Arte. Tradução de Leandro Konder. 5. ed. Rio de Janeiro: Zahar Editores 1976, p. 7-10.

CARDOSO, Fernando da Silva; GOMES, Graciele. Maria Coelho de Andrade; CARVALHO, Mario de Faria. Memória, imaginário e subjetividade: notas a uma categoria estética à rememoração da história de horror brasileira. Diálogos Latinoamericanos, v. 20, n. 28, p. 117, 2019. Disponível em: https://tidsskrift.dk/dialogos/article/view/118001/166024. Acesso em: 12 jan. 2020.

CARVALHO, Mario de; CARDOSO, Fernando da Silva. Contemporaneidade, Pesquisa Social e Imaginário. Revista NUPEM (Online), v. 7, p. 105-117, 2015. Disponível em: http://www.fecilcam.br/revista/index.php/nupem/article/viewFile/793/603. Acesso em: 05 jan. 2020.

CARVALHO, Mario de Faria; GOMES, Graciele Maria Coelho de Andrade. Da racionalidade à subjetividade: educação estética e sensibilidades nas cartas de Friedrich Schiller. Quaestio - Revista de Estudos em Educação, v. 21, n. 3, p. 693-707, dez. 2019. Disponível em: http://periodicos.uniso.br/ojs/index.php/quaestio/article/view/3347/3485. Acesso em: 18 jan. 2020.

DUARTE JÚNIOR, João Francisco. O sentido dos sentidos: a educação (do) sensível. 233 f. 2000. Tese (Doutorado em Educação) - Programa de Pós-graduação em Educação, Universidade Estadual de Campinas, Campinas, São Paulo. 
DURAND, Gilbert. As estruturas antropológicas do imaginário. 4. ed. Lisboa: Presença, 2012.

FISCHER, Ernst. A necessidade da Arte. Tradução de Leandro Konder. 5. ed. Rio de Janeiro: Zahar Editores. 1976.

FREIRE, Paulo. Educação como Prática da Liberdade. 19. ed. Rio de Janeiro: Paz e Terra, 1989.

FREIRE, Paulo. Pedagogia do Oprimido. Rio de Janeiro: Paz e Terra, 1987.

FOUCAULT, Michel. A hermenêutica do sujeito. Tradução de Márcio Alves da Fonseca e Salma Tannus Muchail. 2. ed. São Paulo: Martins Fontes, 2006.

GOMES, Graciele Maria Coelho de Andrade. Diálogos entre arte e educação: a educação estética a partir da análise sensível da obra de Abelardo da Hora. 172 f. 2019. Dissertação (Mestrado em Educação) - Programa de Pós-graduação em Educação Contemporânea, Universidade Federal de Pernambuco, Caruaru, Pernambuco.

GOMES, Graciele Maria Coelho de Andrade; CARVALHO, Mário de Faria. Aesthetic Education and Sensitivity from the Thought of Friedrich Schiller. Art\&Sensorium, Curitiba, v. 5, n. 2, p. 125 - 135, jul.-dez., 2018. Disponível em:

http://periodicos.unespar.edu.br/index.php/sensorium/article/view/2348/1676. Acesso em: 01 dez. 2019.

GOMES, Graciele Maria Coelho de Andrade; CARVALHO, Mário de Faria. Bases sensíveis para pensar a educação popular à luz do muralismo mexicano: notas a partir da obra o primeiro encontro, de Aurora Reyes. In: Encontro de estudos multidisciplinares em cultura, v. 15, 2019, Salvador. Anais. Salvador: UFBA, 2019, p. 1-15. Disponível em: http://www.enecult.ufba.br/modulos/submissao/Upload-484/111537.pdf. Acesso em: 21 jan.2020.

HERMANN, Nadja. Ética e estética: a relação quase esquecida. Porto Alegre: EDIPUCRS, 2005.

HERMANN, Nadja. "O outro na intersubjetividade". In: Bombassaro, Luiz Carlos; DALBOSCO, Claudio Almir; KUIAVA, Evaldo Antonio. Pensar sensível: homenagem a Jayme Paviani. Caxias do Sul: EDUCS, 2011, p. 433-443.

JUNG, Carl Gustav. Métamorphoses symboles de la libido. Montaigne, Paris, 1932.

KANT, Immanuel. Crítica da razão pura. Tradução de Fernando Costa Mattos. 4. ed. Petrópolis, Rio de Janeiro: Vozes; Bragança Paulista, SP: Editora Universitária São Francisco, 2015.

LARROSA, Jorge. Pedagogia Profana: danças, piruetas e mascaradas. Tradução de Alfredo Veiga-Neto. 4. ed. Belo Horizonte: Autêntica, 2006.

MAFFESOLI, Michel. Elogio da razão sensível. Tradução de Albert Chrisphe Migueis Stuckenbruck. Petrópolis: Vozes, 1998. 
MAFFESOLI, Michel. No fundo das aparências. Tradução de Bertha Halpern Gurovitz. Petrópolis: Vozes, 1996.

MARTINS, Mirian Celeste; PICOSQUE, Gisa; GUERRA, M. Terezinha Telles. Didática do ensino de arte: a língua do mundo. São Paulo: FTD, 1998.

NIETZSCHE, Friedrich. Além do bem e do mal ou prelúdio de uma filosofia do futuro. Tradução de Márcio Pugliesi. Curitiba: Hemus, 2004.

NIETZSCHE, Friedrich. Assim falava Zaratustra. Versão para E-books. E-books Brasil, 2002. Acesso em: 21 set. 2018.

READ, Herbert. A educação pela arte. Tradução de Valter Lellis Siqueira. São Paulo: Martins fontes, 2001.

ROLNIK, S. Arquivo para uma obra-acontecimento: projeto de ativação da memória corporal de uma trajetória artística e seu contexto. São Paulo: Sesc, 2011.

SCHILLER, Friedrich. A educação estética do Homem. Tradução de Roberto Schwarz e Márcio Suzuki. 10. ed. São Paulo: Iluminuras, 2017.

SCHILLER, Friedrich. Objetos trágicos, objetos estéticos. Tradução de Vladmir Vieira. Belo Horizonte: Autêntica, 2018.

SCHOPENHAUER, Arthur. O mundo como vontade e representação. Tradução de Jair Barboza. São Paulo: Ed. Bras. UNESP, 2005.

SOARES, Rosana. A educação estética como possibilidade de emancipação dos sujeitos no ensino da arte: desdobramentos e implicações. 283 f., 2015. Tese (Doutorado em Educação), Programa de Pós-graduação em Educação, Universidade Federal da Bahia, Salvador, Bahia.

SUASSUNA, Ariano. Iniciação à estética. 12. ed. Rio de Janeiro: José Olímpio, 2012.

SÜSSEKIND, Pedro. O impulso lúdico: sobre a questão antropológica em Schiller. Artefilosofia. Ouro Preto, n. 10, p. 11-24, 2011. Disponível em: http://www.periodicos.ufop.br/pp/index.php/raf/article/view/611. Acesso em: 05 abr. 2018.

WILLMS, Elni Elisa; ALMEIDA, Rogério de; BECCARI, Marcos. (org.). Diálogos entre arte, cultura \& educação. São Paulo: FEUSP, 2019. 